\title{
Rethinking Redistricting: How Drawing Uncompetitive Districts Eliminates Gerrymanders, Enhances Representation, and Improves Attitudes toward Congress
}

\author{
Thomas L. Brunell, University of Texas at Dallas
}

\section{Introduction}

In every contested election there are inevitably winners and losers, both among the candidates and among the voters. Some candidates will take their seats as elected officials, and others will not. Some voters will be happy with the outcome, others will not. Here I seek to better understand the relationship between whether a voter casts a ballot for the winning candidate in U.S. House elections and that voter's evaluations of her representative. I build on a burgeoning literature on the relationship between voters and their elected governments to derive and test a theory about this connection. The data will show that voters whose preferred candidate wins a seat in the House of Representatives are systematically happier with their representative than those voters whom did not vote for the winning candidate. While this finding is not especially groundbreaking, the implications for the way in which we draw congressional and state legislative district lines are quite provocative. Specifically, since district lines in the House are necessarily an artificial construct, I argue that map makers ought to "pack" districts with as many like-minded partisans as possible. Trying to draw "competitive districts" 1 effectively cracks ideologically congruent voters into separate districts, which has the effect of increasing the absolute number of voters who will be unhappy with the outcome and dissatisfied with their representative. I discuss the benefits of fundamentally rethinking the way in which we draw congressional and state legislative districts, as well as address likely concerns that might be raised about drawing districts this way.

Thomas L. Brunell is associate professor of political science in the school of social sciences at the University of Texas at Dallas. His research interests include Congress, elections, redistricting, political parties, and interest groups.

\section{Winners and Losers}

A developing literature suggests that voters' evaluations of government, including overall trust in government, is directly related to whether they cast a ballot for the winning candidate. Anderson and LoTempio (2002) show that citizens who voted for the winning presidential candidate have significantly higher levels of overall trust in government relative to voters whose candidate lost the election (even after controlling for other factors that affect trust). Thus, evaluations of the government depend, in part, on election outcomes. However, Anderson and LoTempio find no relationship between votes for congressional candidates and overall trust in government, although this is likely because voters are more likely to think about the president than Congress when asked how much trust they have in the federal government. ${ }^{2}$ Clarke and Acock (1989) show that voting for the winning candidate in American elections increases voter efficacy as well.

These results are not unique to the American case. Anderson and Guillory (1997) demonstrate that a similar relationship exits in other advanced industrial democracies. Clarke and Kornberg (1992) show that winning voters in Canada have more positive evaluations of their members of parliament in terms of responsiveness to voters. This "winning effect" extends not only to voters, but also to the candidates who stand for election. Bowler and Donovan (2002) demonstrate that elites' attitudes toward electoral institutions are, in part, dependent on whether they win the election. Winning candidates, who have been delivered to parliament by the current electoral arrangement, are much more satisfied and committed to these institutions than are losing candidates.

\section{Theory and Data}

The theory driving this investigation is simple: citizens who vote for the win- ning candidate in a House election will be systematically more likely to have higher evaluations of said candidate relative to voters who vote for the losing candidate. Similarly, "winning" voters will have more positive and fewer negative things to say about their representative than "losing" voters. I test this proposition using the American National Election Study (ANES) cumulative file with survey data from 1948-2000, although the multivariate analysis only includes data from 1980 on, as some of the variables utilized in the analysis were not part of the survey until that time.

\section{Empirical Results}

Using these data I test to see what effects voting for the winning candidate in a U.S. House of Representatives election has on evaluations of that representative, as well as voter evaluations of Congress as an institution. First, I examine the relationship between which candidate a respondent has voted for and that voter's affect toward the representative. In the National Election study, respondents are asked the following open-ended question: "Is there anything in particular that you liked about [U.S. House incumbent candidate] What is that? Anything else?" They are also asked if there is anything that they dislike about the incumbent representative. The survey records up to four responses for both likes and dislikes. Affect for a candidate is simply measured as the number of likes minus the number of dislikes. So if a voter has four positive and one negative things to say, the result is an affect of +3 . This variable ranges from +4 to -4 . Table 1 presents the results of a cross tabulation of affect for the incumbent and whether the respondent had voted for this candidate or an opponent (same party, different party). Clearly, the results indicate that when people vote for the winner, their affect for their representative is significantly more positive. The percentage of people who voted for the losing candidate and 
Table 1

\section{Relationship between Voting for Winning Candidate and Likes Minus Dislikes for the Incumbent Representative}

\begin{tabular}{cccc}
\hline $\begin{array}{l}\text { Incumbent Affect } \\
\text { (likes-dislikes) }\end{array}$ & Losing Voter & Winning Voter & Total \\
\hline-4 & 62 & 7 & 69 \\
-3 & $1.9 \%$ & $0.1 \%$ & $0.8 \%$ \\
-2 & 97 & 23 & 120 \\
& 2.9 & 0.4 & 1.4 \\
-1 & 218 & 79 & 297 \\
& 6.6 & 1.5 & 3.4 \\
0 & 363 & 175 & 538 \\
& 10.9 & 3.3 & 6.2 \\
1 & 1,241 & 1,556 & 2,797 \\
& 37.3 & 29.3 & 32.4 \\
2 & 528 & 1,204 & 1,732 \\
& 15.9 & 22.7 & 20.0 \\
3 & 457 & 1,104 & 1,561 \\
& 13.7 & 20.8 & 18.1 \\
4 & 217 & 682 & 899 \\
& 6.5 & 12.8 & 10.4 \\
Total & 143 & 486 & 629 \\
& 4.3 & 9.1 & 7.3 \\
& 3,326 & 5,316 & 8,642 \\
\hline
\end{tabular}

Entries represent the number of respondents from the cumulative American $\mathrm{Na}$ tional Election Study file 1948-2000 (study no. 8475) who answered questions about the number of likes and dislikes they have about their incumbent Representative, column percentages below entries. The overall affect is simply the number of likes (up to 4) minus the number of dislikes (up to 4). Chi-squared $=913.3, p<$ .001. Losing voters are those who reported voting for the candidate in the House election that lost, and winning voters are those who reported voting for the winning House candidate. cumbent, while fully $21.9 \%$ of losing voters disapproved of the incumbent representative. Over $82 \%$ of winning voters express approval of the elected official. These results are not surprising-people who vote for the winning candidate are happier than people who voted for the losing candidate-and they fit with much of the other literature on the subject of how attitudes toward government are conditioned by how people cast their ballots. People are more satisfied with the government (or its component parts) when the candidates that they vote for are elected.

The relationship between winning and losing also moves beyond how a voter feels toward a specific representative. Election outcomes also influence the ways in which citizens connect with Congress as an institution. For instance, Table 4 is a cross-tabulation of a respondent's overall rating of Congress and whether the person they voted for in the House election won. Roughly the same percentage of people rate Congress as doing a "very poor job" in the winning and losing voter columns, so even among voters whose candidate is victorious a substantial number of people remain highly skeptical of our legislature. However, more losing voters rate Congress as doing a "poor job" and more winning voters rate Congress as doing a "good job." While the differences are not as large as those we saw in previous tables, they are statistically significant and any increase in satisfaction with our had more negative than positive things to say (i.e., their affect score is negative) is $22.3 \%$; that same measure for winning voters is only $5.3 \%$. Similarly, voters for the winning candidate are far more likely to have more positive things to say about their incumbent representative than are losing voters. Over $65 \%$ of the people that voted for the winner had more positive than negative things to say. ${ }^{3}$ Table 2 presents the multivariate analysis with the affect variable as the dependent variable. Even after controlling for other variables that influence how a voter might feel about his or her incumbent representative, the "Vote for Winner" variable is positive and statistically significant at beyond the .001 level. Other variables that influence the number of likes and dislikes include age, education, income, party identification, and responses to the congressional thermometer question.

Table 3 displays the relationship between voting for the winner and voter approval of the incumbent. Only $4.8 \%$ of winning voters disapproved of the in-

\section{Table 2}

\section{Explanatory Model for Affect toward the Incumbent}

\begin{tabular}{lcc}
\hline Independent Variable & Coeff. & SE \\
\hline Constant & -1.15 & 0.218 \\
Age (higher = older) & $\mathbf{0 . 0 1 3}$ & 0.002 \\
Gender ( $=$ female) & 0.065 & 0.05 \\
South (1 = from Southern state) & 0.052 & 0.058 \\
Education (higher = more education) & $\mathbf{0 . 0 6 2}$ & 0.019 \\
Income (higher = higher income) & $-\mathbf{0 . 0 6 1}$ & 0.028 \\
Party Id (1 = strong Dem, 7 = strong Rep) & $\mathbf{0 . 0 4 2}$ & 0.012 \\
Congress Thermometer (higher = positive evaluations) & $\mathbf{0 . 0 0 9}$ & 0.002 \\
Federal Govt. Thermometer (higher = positive evaluation) & 0.0002 & 0.002 \\
National Economy (higher = economy doing better) & 0.024 & 0.035 \\
Personal Financial (higher = better financial) & -0.010 & 0.035 \\
Vote for Winner (1 = Resp. voted for winner) & $\mathbf{0 . 8 9}$ & 0.054 \\
N & 3,429 & \\
Adjusted R & & \\
\hline
\end{tabular}

The dependent variable is the number of likes (up to 4 ) minus the number of dislikes (up to four) with respect to the incumbent Representative. Entries are unstandardized OLS regression estimates. Data are from the American National Election Study Cumulative File 1948-2000. Bold entries are statistically significant at $p<$ .05 or better. 


\section{Table 3 \\ Relationship between Voting for the Winning Candidate and Approval of Incumbent}

\begin{tabular}{lccc}
\hline $\begin{array}{l}\text { Approve of House } \\
\text { Incumbent }\end{array}$ & Losing Voter & Winning Voter & Total \\
\hline Approve & 2,033 & 4,447 & 6,480 \\
& $59.5 \%$ & $82.4 \%$ & $73.5 \%$ \\
Disapprove & 750 & 260 & 1,010 \\
& 21.9 & 4.8 & 11.5 \\
Don't Know & 635 & 688 & 1,323 \\
& 18.6 & 12.8 & 15.0 \\
Total & 3,418 & 5,395 & 8,813 \\
& 100 & 100 & 100 \\
\hline
\end{tabular}

Entries represent the number of respondents from the cumulative American National Election Study file 1948-2000 (study no. 8475) who either approve or disapprove of the incumbent Representative, column percentages below entries. Chisquared $=665.8, p<.001$. Losing voters are those who reported voting for the candidate in the House election that lost, and winning voters are those who reported voting for the winning House candidate.

representative institutions is surely a positive development.

The relationship between voting for the winning candidate and which branch of government the respondent trusts most (Congress, the Supreme Court, the president, or political parties) is presented in Table 5. The biggest difference between winners and losers is related to voting for the winning House candidate. More than $23 \%$ of the voters on the losing side versus nearly $32 \%$ of voters whose can- didate won chose Congress as the most trusted branch of the federal government. Thus, winning voters are much more likely than losing voters to choose Congress as their most trusted branch of the federal government. ${ }^{4}$

People who vote for the winning candidate are systematically more satisfied with their representative and with Congress as a whole. But the underlying story is not merely one of winning or losing, but rather ideological distance.

\section{Table 4 \\ Relationship between Voting for the Winning Candidate and Approval of Congress}

\begin{tabular}{lccc}
\hline Performance of & & & \\
Congress Rating & Losing Voter & Winning Voter & Total \\
\hline Very poor job & 389 & 532 & 921 \\
& $31.4 \%$ & $30.3 \%$ & $30.8 \%$ \\
Poor Job & 289 & 333 & 622 \\
& 23.3 & 19.0 & 20.8 \\
Fair Job & 443 & 657 & 1,100 \\
& 35.8 & 37.5 & 36.8 \\
Good Job & 108 & 213 & 321 \\
& 8.7 & 12.2 & 10.7 \\
Very Good Job & 9 & 19 & 28 \\
& 0.7 & 1.1 & 0.9 \\
Total & 1,238 & 1,754 & 2,992 \\
& 100 & 100 & 100 \\
\hline
\end{tabular}

Entries represent the number of respondents from the cumulative American $\mathrm{Na}$ tional Election Study file 1948-2000 (study no. 8475) who indicated how they rate the job that Congress is doing, column percentages below entries. Chi-squared $=$ $16.4, p<.003$. In the original dataset there are nine valid responses to the dependent variable, here they have been collapsed. Losing voters are those who reported voting for the candidate in the House election that lost, and winning voters are those who reported voting for the winning House candidate.
The greater the distance between the representative and the voter, the more likely the voter will be dissatisfied. ${ }^{5}$

\section{Implications}

Based on these results, and since congressional districts are necessarily artificial constructs, there are clearly reasons to draw districts in such a manner as to increase efficacy and happiness with our government, particularly since Congress almost always has significantly lower approval ratings than the president, the Supreme Court, and state governments (see Hibbing and Smith 2001; Hibbing and Theiss-Morse 1995). Packing districts with like-minded partisans makes a great deal of sense, as long as both major political parties are packed to similar degrees. Drawing competitive districts or systematically "cracking" 6 one party or the other is not beneficial and ought not be present in redistricting plans. Thus, what we think of typically as competitive districts (those with roughly equal numbers of Democrats and Republicans) provide negligible benefits and come with significant costs. One of the most significant benefits from drawing a legislative map with packed districts is that it makes it significantly more difficult to effect a map that constitutes a partisan gerrymander. Districting plans that dilute one party's vote must use a combination of packing and cracking to create a map that contains significant levels of partisan bias (i.e., where one party might win the statewide vote for the House, but still end up with fewer seats).

Preserving communities of interest is one of the main principles guiding map makers. Among these principles, preserving communities of interest is certainly the most ephemeral. What really constitutes a community of interest? Is any American city or county, really a community of interest? Sometimesdepending on the issue. A city is a unified community of interest when the issue is non-partisan, for example if the issue is obtainment of federal funds to repair bridges and roads, but it is not if the issue involves anything with ideological disagreement. Properly conceived, I argue, communities of interest should be composed entirely of either Democrats or Republicans (liberals or conservatives) in reflection of the primary cleavage in American politics (Poole and Rosenthal 1991). On controversial issues, ideological communities of interest will typically face issues in unison, increasing the likelihood that their representative will vote on legislation in Congress in congruence with the 


\section{Table 5 \\ Relationship between Voting for the Winning Candidate and Which Branch of Government a Citizen Trusts the Most}

\begin{tabular}{lccc}
\hline Branch Respondent & & & \\
Trusts the Most & Losing Voter & Winning Voter & Total \\
\hline Congress & 137 & 245 & 382 \\
& $23.2 \%$ & $31.7 \%$ & $28.0 \%$ \\
Supreme Court & 267 & 330 & 597 \\
& 45.3 & 42.6 & 43.8 \\
President & 170 & 187 & 357 \\
& 28.8 & 24.2 & 26.2 \\
Political Parties & 16 & 12 & 28 \\
& 2.7 & 1.6 & 2.1 \\
Total & 590 & 774 & 1,364 \\
& 100 & 100 & 100 \\
\hline
\end{tabular}

Entries represent the number of respondents from the cumulative American National Election Study file 1948-2000 (study no. 8475) who chose each branch of the federal government that "they trust the most," column percentages below entries. Chi-squared $(3 \mathrm{df})=13.99, \mathrm{p}<.003$. Losing voters are those who reported voting for the candidate in the House election that lost, and winning voters are those who reported voting for the winning House candidate. vast majority of their constituents. Citizens living in knife-edged districts cannot expect this kind of representation. Drawing districts to increase competitiveness in the general election only optimizes the number of voters that will be upset with their representation. Thus, not only do competitive districts not provide a social "good," they actually increase dissatisfaction and make it less likely that voters' preferences are represented in government.

Drawing competitive districts also increases the volatility of the electoral system. If every district is a "50-50" district, then any small change in the voting behavior of the electorate could produce enormous changes in the partisan distribution of seats. While it is true, and oft-cited, that the Founders intended for the House to most closely mirror the wishes of the public, it is not reasonable to assume that they expected the institution to be hyper-sensitive to relatively small changes in the partisan leanings of the people. Districting this way also delivers a disproportionate share of the voting power to independents and moderate swing voters. ${ }^{7}$ A district that packs voters from both major parties equally into districts (i.e., the average district is either $80 \%$ Republican or $80 \%$ Democratic) has the added benefit of sending congressional delegations to the House that closely mirror the overall distribution of partisans in that state. A plan with many competitive districts can easily send a delegation to the House that is truly unreflective of the underlying partisan divisions in a state.
Some states, like Arizona, ${ }^{8}$ have passed laws or referenda specifying that a districting plan ought to maximize the number of competitive districts. This is not particularly surprising since the common wisdom among most voters and certainly among the media is that the House of Representatives does not have enough competitive districts currently, and that an increase in the number of competitive elections or in the amount of turnover in Congress will somehow enhance representation. There is absolutely no evidence that this is the case. ${ }^{9}$ In fact, maximizing competitive districts is harmful rather than beneficial in many respects. The most obvious effect of drawing cracked or competitive districts is to maximizes the number of voters who are dissatisfied with their representation. ${ }^{10}$ Second, a state that draws all or most of its districts in this knife-edged fashion increases the likelihood that small swings in voting behavior translate into large swings in the percentage of seats that one party can win in a single election. This can result in statewide representation that is widely incongruent with statewide partisanship, which, in turn, leads to voting behavior in the legislature that does not accurately represent the views of the constituents.

From a utilitarian perspective, the ideal congressional district is one populated entirely by people with the same political preferences. Such a constituency would see its wishes effectively translated into votes by their representative and this type of district assures that the representative will remain faithful to the voters through the threat of a primary challenge. Minimizing the ideological distance between the average voter and the likely representative fosters more effective representation and makes it easier for elected officials to discern our preferences, thus strengthening the bonds between the represented and representatives. Buchler (2005) develops this idea more formally and finds that homogeneous non-competitive districts "do a better job than competitive districts in achieving representative outcomes." Further, these districts "produce legislators that are closer to their district medians and more representative of everyone in their district" (457).

The House of Representatives ought to be the closest of our national institutions to the people. We want the connection between the representative and the represented to be a close and faithful connection. The delegate theory of representation "posits that the representative ought to reflect purposively the preferences of his constituents" (McCrone and Kuklinski 1979, 278). Research on the connection between elected officials and the people that they represent has a long tradition in our discipline. Miller and Stokes's (1963) seminal piece on this subject called into question the ability of the representative to know what her constituents want, as well as the ability of the constituents to know and understand how the elected official is voting in Washington.

For example, Miller and Stokes (56) conclude: "The Representative has very imperfect information about the issue preferences of his constituency, and the constituency's awareness of the policy stands of the Representative ordinarily is slight." While other scholars have pointed out some methodological concerns with the original Miller and Stokes study and have questioned the validity of some of their conclusions (see Erikson, Luttbeg, and Holloway 1975; Erikson 1978), there is very little doubt that these connections between the representative and the constituency could be much stronger. Creating packed ideological districts will necessarily strengthen these bonds. If a Democrat is sent to Congress from a district heavily populated by likeminded partisans, she will have little doubt as to how her constituents prefer her to vote on policy proposals. Similarly, creating more "winners" out of voters alleviates some of the uncertainty with respect to how the representative votes on their behalf. This will also serve to encourage representatives to be more responsive to constituent needs.

Elections serve as the main catalyst for keeping representatives faithful to 
their constituents. The threat of being replaced in a popular election incentivizes elected officials to respond to what their constituents want. A districting plan that maximizes the number of winners would clearly affect election outcomes. Most obvious is the likelihood that general election outcomes would not be particularly close. Districts packed with $80 \%$ or more of one party will deliver general election victories to the majority party in the district. Redistricting is already the oft-accused suspect of the decline of competition and turnover in the House of Representatives (Cox and Katz 2002; Hirsch 2003) and this type of plan may not help the current public image of this process. However, it is critical to keep in mind that general election competitiveness is neither a necessary nor sufficient condition for ideal representation. First, we utilize a two-stage process for electing members of Congress, where citizens are given the ability to choose, via a primary election, which candidate will represent their party in the general election. ${ }^{11}$ Therefore, even in an 80-20 district, the incumbent can easily be removed if he fails his constituents. This type of districting plan encourages intrarather than inter-party competition. By no means do homogeneous districts spell an end to electoral competition or responsiveness on the part of our elected officials. Increasing the relevancy of primaries may have other beneficial effects: turnout in primary elections might increase, the organized political parties may be more apt to get involved at the primary election stage, and more qualified candidates may choose to run against an incumbent in a primary. Another reason that incumbents, even in the absence of tough general election competition, will remain faithful to their constituents is that the specter of losing the next election is always prevalent in the minds of incumbents; this implied threat is what keeps our elected officials responsive.

There exists, I argue, sufficient uncertainty among elected officials with respect to their ability to win the next election which keeps them from behaving in ways that might contribute to a loss. My argument is not novel. David Mayhew wrote in 1974 that: "It is possible to conceive of an assembly in which no member ever comes close to losing a seat but in which the need to be reelected is what inspires members' behavior. It would be an assembly with no saints or fools in it, an assembly packed with skilled politicians going about their business" (37). In Unsafe at any Margin Thomas Mann (1978) argued that congressional elections were becoming less

Figure 1

\section{The Relationship between Margin of Victory and Ideology in the House}

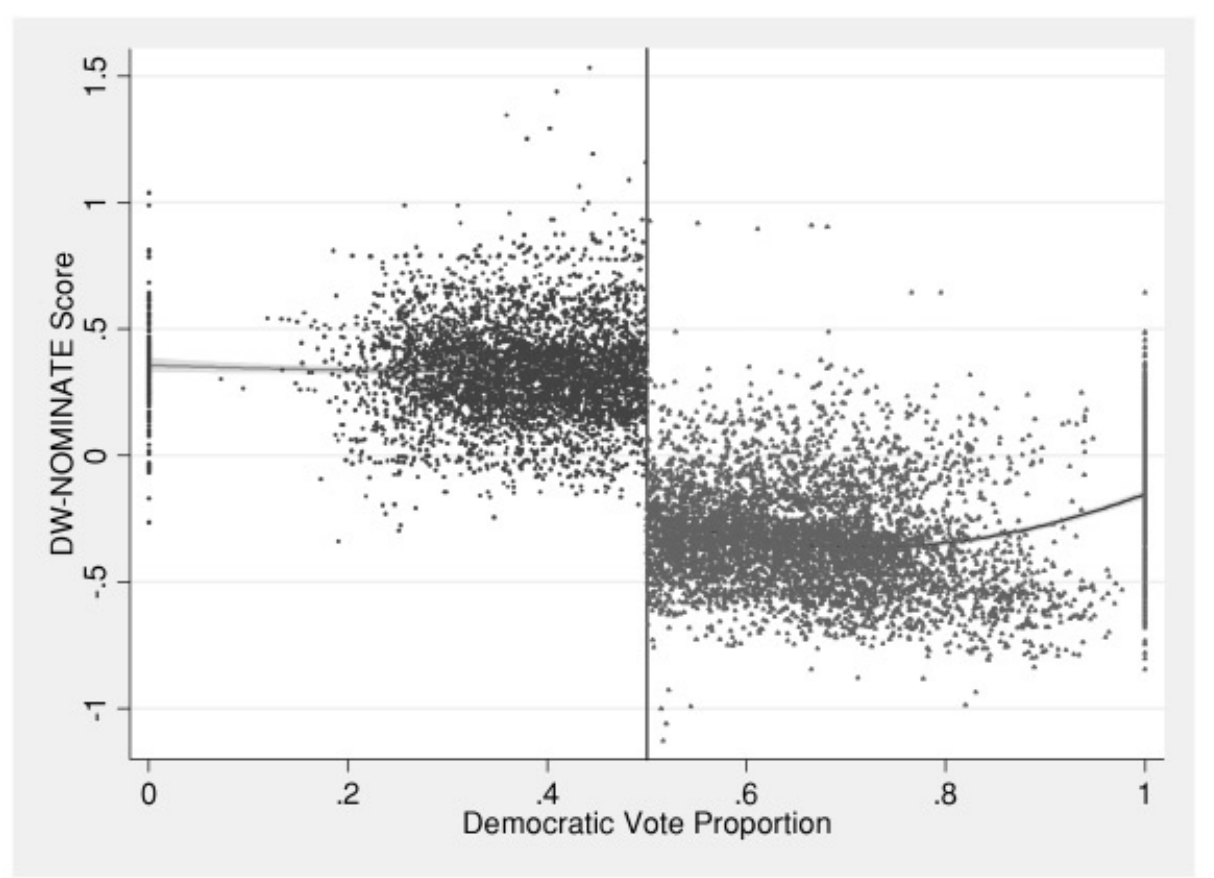

*The graph depicts the quadratic regression line for DW-NOMINATE scores regressed on margin of victory (done separately for Democrats and Republicans). The vertical line at .5 separates Republicans (to the left of the line) from Democrats (to the right of the line). The sample size for the regression models are 4,627 for Republicans and 6,318 for Democrats.

nationalized and election outcomes depended heavily upon what the voters in each district thought of their representative. "Candidate saliency is a doubleedged sword for incumbents; while it can mean an enormous advantage in visibility over challengers, it can also spell disaster if the voters come to believe that their representative has some personal failing" (103).

The lack of turnover in the U.S. Congress should not be used as an indication that our federal institutions are failing as components of a democracy. While I am not arguing that stagnation is the signature of a perfectly health democracy, I do not see rapid replacement of incumbents as a necessary part of a truly representative institution. Indeed, if we want rapid turnover in our legislature, then term limits are a vastly more effective method of producing this outcome than drawing competitive districts. Many 50-50 districts end up with an incumbent who can use the perks of the office to leverage what might have been a competitive district in one election into a very safe seat for many successive elections.

One common objection to this method of districting is that it would add to the polarization in Congress by creating overwhelmingly Republican (Democratic) districts that are more likely to elect very conservative (liberal) members. This is an empirical question that is easily addressed. The question is whether members who win by large margins are more extreme than their colleagues who win by relatively small margins. Figure 1 plots member ideology by vote percentage for the years 1952-2000. The x-axis represents the Democratic proportion of the vote, so very small values indicate Republican victors by very large margins. The closer one moves toward the vertical line at .5 , the more competitive the elections. The data on the far right side of the graph (those data points near 1.0) are districts in which the Democrat won by very large margins. The solid line is the predicted values from a quadratic regression and the shaded regions represent the $95 \%$ confidence region. If so-called safe seats elected more ideologically extreme members we would expect the predicted lines to slope downward for the Democrats as we move along the $\mathrm{x}$-axis toward 1 . The line is more or less straight with a slight upward slope (driven mainly by uncontested elections). For the Republicans we would expect the line to be much higher (i.e., more conservative NOMINATE scores) for values 
close to 0 relative to values close to .5 . The predicted line here is completely flat. Thus, as the margin of victory increases for members to the U.S. House, we seen no real change in the ideology of the members who are elected. ${ }^{12}$ Thus, there is no reason to expect that packing districts on the basis of ideology will have any influence on the ideology of the House as a whole.

\section{Example}

Imagine a state with sufficient population for two congressional districts. The state is perfectly segregated from east to west in terms of partisanship with all Democrats living in the western half of the state and all Republicans living in the eastern half. Further assume that the number of Democrats and Republicans is exactly equal. Given the restrictions of equal population, contiguity, and compactness there are still many different ways in which to cut the state into two districts. Consider three different scenarios.

The first is a line bisecting the state from east to west creating two 50-50 districts. If a state preferred "competitive districts" this would be the most efficient method. From the outset, it is noncontroversial to say that this state should elect, and is best represented by, one Democrat and one Republican. But by creating two competitive districts this significantly increases the odds that one party can sweep the state even with just a very small shift in voting behavior. If the Democrats run a particularly effective campaign and swing $1 \%$ of the vote statewide, this leaves nearly half the state with no ideological representation in the House. Furthermore, even if the election outcome delivered one seat to each party, this still leaves roughly half the state unsatisfied with their own representative because of the way in which the districts were drawn.

Second, we draw two districts, each of which is $75 \%$ one party and $25 \%$ the other. This would create districts that are beyond the bounds of "competitiveness" insofar as the favored party ought to have little trouble electing a candidate of their choice. The overall representation will mirror the statewide breakdown, but this districting plan also leaves a quarter of the state unsatisfied with their representative and less likely to feel efficacious with respect to electing members of Congress.

Last, we bisect the state from north to south, creating two homogeneous partisan districts. Here too the state's representation will mirror the overall partisanship of the state, and all citizens end up voting for a representative that they like and are more likely to highly value the job that their Representative does in the House. These districts will elect people neither less responsive to the wishes of the electorate, nor more extreme in their partisan leanings than any other configuration of districts.

\section{Impact on Traditional Redistricting Principles}

The decennial task of redrawing district lines for U.S. House elections is always a bitterly partisan affair. Since redrawing the maps is done at the state level, district lines depend in large part upon which party controls the state legislature and the governorship. However, many districting plans, regardless of the partisan composition of the state government, end up being litigated over a variety of issues.

The first principle used to guide map makers is equal population. Courts have often tossed out maps that have even the slightest deviation in population across districts within a state (the original federal district court decision in the Vieth $v$. Pennsylvania is a good example). This stems from the one person-one vote principle outlined in two 1964 Supreme Court decisions (Reynolds v. Sims and Wesberry v. Sanders). Packing districts with partisans would not violate this guideline.

Second, districts must be contiguous, which is to say that every point in the district must touch an adjacent point. Districts cannot be made up piecemeal across the state. Again, contiguity could easily be preserved with the method outlined in this paper.

Third, districts are supposed to be compact. Compactness is, at least in part, in the eye of the beholder. A compact district tends to be one whose shape is pleasing to the eye, which is to say, a reasonably shaped polygon. However, oftentimes a district may look like a bug splat on the windshield of a car. Compactness is rarely an issue in court, although it can be, depending upon the judge or judges involved. Creating packed partisan districts may tend to involve drawing districts that are less pleasing to the eye and less compact, although this is a relatively small price to pay for the benefits of having districts in which most voters are winners.

Fourth, map makers strive to "preserve communities of interest." This may be the single most fleeting guideline in district drawing. What constitutes a community of interest? A city? A county? Any geographic region marked by even the slightest bit of partisan di- versity is not a community of interest. A county with a significant population cannot really be thought of as a community of interest on any issue other than one that affects the community directly in a clearly positive or negative way (i.e., putting a nuclear storage facility in the county, or a federal grant to the county to improve roads). Typically in court, competing maps try to quantify the preservation of communities of interest by counting the number of city and county splits or segments (Plan A splits four of the 26 counties into separate districts, Plan $B$ splits six of the 26 counties, etc.). In court, protecting communities of interest generally devolves into a beauty contest to see which map can keep as many counties and municipalities whole. As I argued above, communities of interest are better thought of in terms of overall ideological congruence among citizens, rather than in geographic considerations. Thus, the overall compactness of districts, at times, will be sacrificed if this method were used, but again, geography should not be a sacred cow in the redistricting process. ${ }^{13}$

Lani Guinier is a vocal critic of the single-member district system widely used in American elections. Guinier and I agree that using geography as one of the central principles for drawing districts is often harmful rather than beneficial. She writes:

Winner-take-all territorial districting imperfectly distributes representation based on group attributes and disproportionately rewards those who win the representational lottery. Territorial districting uses an aggregating rule that inevitably groups people by virtue of some set of externally observed characteristics such as geographic proximity or racial identity. In addition, the winner-take-all principle inevitably wastes some votes. The dominant group within the district gets all the power; the votes of supporters of nondominant groups or of disaffected voters within the dominant group are wasted. Their votes lose significance because they are consistently cast for political losers. (Guinier 1993)

Where Guinier and I depart company is the necessity of wasting votes in a single-member district system. I advocate that we minimize the number of wasted votes, which makes her distinction between dominant and nondominant groups less important as the nondominant group is redrawn from several districts into their own district in which they are dominant (and a new nondominant group is not created). Her underlying concern is 
identical to mine- - "votes lose significance because they are consistently cast for political losers."

The Voting Rights Act implicates all the states under Section 2 and many of the states under Section 5 in terms of election law. The Thornburg v. Gingles decision ruled that districting plans must take care to ensure that minority votes are not systematically diluted, although subsequent decisions have held that race cannot be used as the predominant factor in drawing districts (Shaw v. Reno; Bush v. Vera). Packing districts on the basis of ideology would not interfere with districting plans satisfying the requirements of the Voting Rights Act. In fact, using ideology rather than race, but still preserving the ability of protected minorities to have a reasonable opportunity to elect a candidate of their choice, would be relatively easy to accomplish.

\section{Discussion}

Conventional wisdom suggests that drawing competitive legislative districts is beneficial to our system of government. In fact, drawing districts with relatively equal numbers of Democrats and Republicans maximizes the number of losing voters (also known as wasted votes). A voter on the losing side of an election is systematically more likely to be unhappy with his representative and with Congress as an institution. Further, the assumption that competitive general elections make representatives more responsive is also wrong. The implied threat of competition, especially at the primary level, is sufficient to keep our elected officials faithful to our opinions. Furthermore, this method of districting is not the end of electoral competition; rather it refocuses the nexus of competition from inter to intra-party. Even if a voter, in a packed district, casts a ballot for the candidate that ends up losing in the dominant party's primary, she still has the opportunity to cast a ballot for the winning candidate in the general election.

Maximizing the number of competitive districts vastly increases the likelihood that very small changes in the partisan leanings of voters nationwide get translated into very large swings in congressional seats. While political analysts oftentimes fall into the trap of trying to gauge the relative health of American democracy through the amount of turnover, or the lack thereof, in the U.S. Congress, this is not at all an appropriate method of estimating how well our democratic institutions are functioning. Volatility in Congress is not a goal we ought to be striving for when we draw legislative maps. If the American people truly pine for turnover even drawing competitive districts is no guarantee, rather we should institute term limits. ${ }^{14}$ While turnover and volatility may decrease using this method, the critical aspect of the plan to keep in mind is that the overall distribution of seats will closely mirror the distribution of preferences in each state and nationwide. The goal of redistricting is not to maximize the number of seats that switch from one party to the other every two years; rather the goal of redistricting is for the House to pass legislation in such a way that policy preferences among the electorate are reflected in policy outputs. Drawing districts on the basis of ideology satisfies this goal, while drawing competitive districts does not.

Drawing districts packed with either like-minded partisans maximizes the numbers of winning voters in legislative elections. Packing districts with ideologically like-minded individuals will not elect more extreme candidates and ought to strengthen the bonds between the representatives and their constituents. Inferring how the electorate wants a representative to vote on an issue will be much simpler when one's district is significantly more homogeneous. If this type of districting plan were put into effect it may also stimulate more competition in primary elections. While general elections to the House of Representatives would surely be a largely unexciting affair, primary elections could rise in importance and become the more likely mechanism for replacing members. Organized political parties often seek to suppress competition at the primary election stage largely because they do not want to reduce their party's chances of winning the general election. If the likelihood of winning the general election is overwhelmingly in favor of one party or the other, this risk is alleviated and ought to remove this barrier.

Packing partisans also significantly reduces the ability of map-makers to effect a significant partisan gerrymander. It is through the combination of packing and cracking that one party can effectively dilute the votes of their opposition. As long as districts are packed with nearly equal proportions in terms of the two major parties, the overall representation ought to closely mirror the distribution of partisanship statewide. This does not mean that both parties have equal numbers of districts-if the Democrats outnumbered Republicans 2 to 1 in the state, there will still be more Democratic districts-the critical component is that the ratio of the majority party to the minority party in each district be roughly equal across the state.

This method is probably best thought of as functionally equivalent to statebased proportional representation. ${ }^{15}$ One of the positive attributes of proportional representation is the absence of "wasted votes" (i.e., people that vote for the losing candidate in the general election). Single-member district systems, especially those with many competitive districts, end up wasting the votes of millions of people. If we pack districts, the number of wasted votes would be at a minimum, while still keeping the single-member district system to which Americans have grown accustomed. Lani Guinier is a vocal critic of the singlemember district system used in the House. One of her most powerful criticisms is that the redistricting process will inherently result in a gerrymander because "in essence [redistricting] is the process of distributing wasted votes" (Guinier 1993). Guinier's fears are rather well founded given the traditional districting process, however much of her concerns generally about single-member districts and the redrawing of their lines disappear using the method outlined in this paper.

For instance, Guinier alludes to the possibility of creating homogeneous districts:

Districts could be made more homogeneous to reduce the number of wasted votes. But this alternative demonstrates the second way that winner-take-all districting wastes votes. When more people vote for the winning candidate than is necessary to carry the district, their votes are technically wasted because they were unnecessary to provide an electoral margin within the district and they could have been used to provide the necessary electoral margin for a like-minded partisan in another district. In other words, packing voters in homogeneous districts wastes votes because it dilutes their overall voting strength jurisdiction-wide.

This is an important point insofar as a gerrymander is only possible when the combination of packing and cracking districts is utilized. However, if all districts are packed then the real problem Guinier addresses above is solved. Votes in packed districts are not effectively wasted because all districts are packed, and the overvotes could not be used to help a like-minded partisan in another district. 
District lines are artificial and we ought to use this distinction to serve our collective advantage. Let us create more winners out of voters and increase the satisfaction with our members of Congress and Congress as an institution by rethinking the way in which we draw these lines. Map makers ought

\section{Notes}

*I would like to thank Jim Adams, Valerie Brunell, Bruce Cain, Geoff Evans, Bill Koetzle, Bernie Grofman, Sam Hirsch, Michael D. McDonald, Iain McLean, Sam Merrill, Glenn Phelps, David Rueda, Alec Stone Sweet, Chris Wlezian, and the Politics Group at Nuffield College for their comments.

1. Throughout this paper "competitive districts" refers to a district drawn with relatively equal numbers of voters that favor the two major parties. This is to say there is some probability that the general election will be relatively competitive (although it is certainly not a guarantee of competitiveness).

2. They tested both voting for the winning candidate in an election and voting for the party that wins a majority in Congress; neither model yielded statistically significant results.

3. Of course this is not all voters, but rather the sub-sample of voters who answered this question.

4. This relationship remains positive and statistically significant in a multivariate model.

5. See Buchler (2005) for a formal treatment of this relationship.

6. Cracking refers to the art of drawing districts that are close to being competitive but give one party the edge in an election. For instance, if the Democrats control the redistricting process they are likely to draw districts that lean to be less concerned with keeping counties or municipalities whole, and concentrate on keeping ideologically likeminded individuals in the same district. This change would fortify the bonds between voters and elected officials and transfer the locus of competition in congressional elections from inter- to intra-party. Lastly, it is clear that we cannot rely on the courts to strike down gerrymandered redistricting plans. ${ }^{16}$ By instituting the method advocated in this paper, the likelihood of a significant partisan gerrymander by either political party is greatly reduced. toward the Democratic candidate-55\% Democrat, $45 \%$ Republican. Although map makers need to be careful not to draw these too competitive as small swings in the vote could then reverse these districts and instead of a Gerrymander you end with what Grofman and Brunell (2005) call a Dummymander.

7. For instance if a district is $45 \%$ Republican, $45 \%$ Democratic and 10\% Independent, the only votes that matter are those from the smallest group. These independents will only be able to choose from either a Democrat or a Republican in the election, but nonetheless, they become the votes that really count.

8. Proposition 206, passed by Arizona voters in 2000, requires: "To the extent practicable, competitive districts should be favored where to do so would create no significant detriment to the other goals" ( $\sec 14$, subsection F).

9. I highly suggest reading the exchange between Issacharoff (2002) and Persily (2002) on the topic of the utility of competition in congressional elections. As both are also law professors they also touch on legal issues and the proper role of courts in regulating elections.

10. In fact competitive districts are optimal in this sense.

11. In terms of incentives for challengers, the opportunity structure of a packed district makes it objectively more attractive for challengers from the dominant party to emerge. One only has to win the primary election in order to take the seat, whereas in a 50-50 district one could face the daunting prospect of hard fought elections in both the primary and general elections.

12. This general trend is true using a wide variety of ideological scores from many different interest groups, see Lee, Moretti, and Butler 2004.

13. If a city or county does also happen to be an ideological community of interest then it ought to be kept in a single district.

14. This should not be taken as an endorsement of term limits, but rather a much more effective method of effecting turnover in Congress than drawing knife-edged districts.

15. It would differ from a proportional representation system insofar as we would still have a two-party system, whereas PR systems tend to increase the effective number of parties.

16. Recently the Supreme Court (Vieth v. Jubuleier, 2003) nearly declared partisan gerrymandering nonjusticiable, which would have made it impossible for courts to declare gerrymandered maps unconstitutional in the future. It remains unclear what standards will be used in the future by judges to decide gerrymandering cases.

\section{References}

Anderson, Christopher J., and Christine A. Guillory. 1997. "Political Institutions and Satisfaction with Democracy: A Cross-National Analysis of Consensus and Majoritarian Systems." American Political Science Review 91 (1): 66-81.

Anderson, Christopher J. and Andrew J. LoTempio. 2002. "Winning, Losing and Political Trust in America." British Journal of Political Science 32: 335-351.

Bowler, Shaun, and Todd Donovan. 2002. "Democracy, Institutions and Attitudes about Citizen Influence on Government." British Journal of Political Science 32(4): 371-390.

Buchler, Justin. 2005. "Competition, Representation, and Redistricting: The Case against Competitive Congressional Districts." Journal of Theoretical Politics 17 (4): 431-463.

Clarke, Harold D., and Alan C. Acock. 1989. "National Elections and Political Attitudes: The Case of Political Efficacy." British Journal of Political Science 19(4): 551-562.

Clarke, Harold D., and Allan Kornberg. 1992. "Do National Elections Affect Perceptions of MP Responsiveness? A Note on the Canadian Case." Legislative Studies Quarterly 17(2): 183-204.

Cox, Gary W., and Jonathan N. Katz. 2002. Elbridge Gerry's Salamander: The Electoral Consequences of the Reapportionment Revolution. Cambridge: Cambridge University Press.

Erikson, Robert. 1978. "Constituency Opinion and Congressional Behavior: A Reexamination of the Miller-Stokes Data." American Journal of Political Science 22(3): 511-535.

Erikson, Robert S., Norman R. Luttbeg, and William V. Holloway. 1975. "Knowing One's District: How Legislator's Predict Referendum Voting." American Journal of Political Science 19(2): 231-246.

Grofman, Bernard, and Thomas L. Brunell. 2005. "The Art of the Dummymander: The Impact of Recent Redistrictings on the Partisan Makeup of Southern House Seats." In Redistricting in the New Millennium, ed. Peter Galderisi. Lanham, MD: Lexington Books.

Guinier, Lani. 1993. "Groups, Representation, and Race-Conscious Districting: A Case of the Emperor's Clothes." Texas Law Review 71: 1589.

1994. The Tyranny of the Majority: Fundamental Fairness in Representative Democracy. New York: Free Press.
Hibbing, John R., and James T. Smith. 2001. "What the American Public Wants Congress to Be." In Congress Reconsidered, $7^{\text {th }}$ edition, eds. Lawrence C. Dodd and Bruce I. Oppenheimer. Washington D.C.: CQ Press.

Hibbing, John R., and Elizabeth Theiss-Morse. 1995. Congress as Public Enemy: Public Attitudes towards American Political Institutions. Cambridge: Cambridge University Press.

Hirsch, Sam. 2003. "The United States House of Unrepresentatives: What Went Wrong in the Latest Round of Congressional Redistricting." Election Law Journal 2(2): 179-216.

Issacharoff, Samuel. 2002. "Gerrymandering and Political Cartels." Harvard Law Review (116): 593-648

Lee, David S., Enrico Moretti, and Matthew J. Butler. 2004. "Do Voters Affect or Elect Policies? Evidence from the U.S. House." Quarterly Journal of Economics 1993(3): 807-859.

Mann, Thomas. 1978. Unsafe at any Margin: Interpreting Congressional Elections. Washington, D.C.: American Enterprise Institute. 
Mayhew, David R. 1974. Congress: The Electoral Connection. New Haven: Yale University Press.

McCrone, Donald J., and James H. Kuklinski. 1979. "The Delegate Theory of Representation." American Journal of Political Science 23(2): 278-300

Miller, Nicholas R. 1983. "Pluralism and Social Choice." American Political Science Review 77: 734-747.

Miller, Warren E., and Donald E. Stokes. 1963.
"Constituency Influence in Congress." American Political Science Review 57(1): 45-56.

Persily, Nathan. 2002. "In Defense of Foxes Guarding Henhouses: The Case for Judicial Acquiescence to Incumbent Protecting Gerrymanders." Harvard Law Review (116): 649-683.

Poole, Keith, and Howard Rosenthal. 1991. "On Dimensionalizing Roll Call Votes in the U.S. Congress." American Political Science Review 85(4): 955-960.
Sapiro, Virginia, Steven J. Rosenstone, and the National Election Studies. American National Election Studies Cumulative Data File, 1948-2000 [Computer file]. 11th ICPSR version. Ann Arbor: University of Michigan, Center for Political Studies [producer], 2002. Ann Arbor: Inter-university Consortium for Political and Social Research [distributor], 2002. 